be a general deterioration in a population of qualities that man has always admired and on the whole striven after. This is a question that would seem to need further attention than it has received. The issue is apt to be side-tracked in countries where modern methods of contraception are widely available by talk of "wanted" and " unwanted " babies. But unfortunately too many babies may be " wanted "-too many, that is, for the well-being of the population even if not for the family into which they are born. The evolution of man has been ruled so far, as Professor Ali Khan says, by the law of natural selection. Man's command over nature now is making him the master rather than the subject of the law in some respects-perhaps in the long run only trivial ones. But it would seem unlikely that he can step outside so pervasive a biological process with impunity unless he discovers some other way of retaining the benefits it blindly conferred.

\section{Accidental Hypothermia}

Two years ago the British Medical Association's memorandum on accidental hypothermia ${ }^{2}$ appeared. At that time knowledge of the condition was based on the experience of individual clinicians supplemented by deductions from what was known about the effects of age, drugs, and disease on temperature control. A recent report of the Committee on Accidental Hypothermia of the Royal College of Physicians ${ }^{3}$ now adds a considerable body of factual information which was previously lacking.

The report is concerned only with patients admitted to selected hospitals scattered between Exeter and Aberdeen during the three months February to April 1966. Records of temperatures at the time of admission of over 18,000 patients were received. Of these, 136 patients had rectal temperatures below $95^{\circ} \mathrm{F}$. $\left(35^{\circ} \mathrm{C}\right.$.). Of 128 case papers examined 126 were accepted as genuine cases of hypothermia and analysed.

There was a correlation between the frequency of cases of hypothermia and the environmental temperature. Substantial numbers occurred when the mean environmental temperature fell below $41^{\circ} \mathrm{F}$. $\left(5^{\circ} \mathrm{C}\right.$.), and the incidence increased as the mean temperature fell lower. Correlation with geographical location was not obvious, and to live in the south-west is certainly not a guarantee against being affected. No age group was immune from danger, but $24 \%$ of all the patients with hypothermia were below the age of 1 year, while $42 \%$ were aged 65 or over.

In 17 of the patients hypothermia was the principal diagnosis ; 10 of them were 65 or over and 4 were under 1 year old. The old people were generally living alone, either in poorly heated homes or sleeping out of doors; the babies had inadequate mothers or cold homes. One child fell into a freezing lake. In the remaining cases other diseases were present. Among the cold infants congenital abnormalities were common; the aged people suffered from cardiovascular disease, diabetic or drug coma, and a variety of other diseases. In a few cases the hypothermia followed injury.

Mortality rates were correlated with the patient's temperature on admission. The patient did not survive with a temperature below $80^{\circ} \mathrm{F}$. $\left(26^{\circ} \mathrm{C}\right.$.), but even when the temperature was between $93^{\circ} \mathrm{F}$. $\left(34^{\circ} \mathrm{C}\right.$.) and $95^{\circ} \mathrm{F} .\left(35^{\circ} \mathrm{C}\right.$.) the mortality reached $30 \%$. The death rate for the whole group of hypothermic cases was $37 \%$ (i.e., 47 patients), and the committee comments that if the group is representative there could have been about 9,000 such patients admitted to hospital in the three-month period. To this estimate must be added those patients who are found dead and not admitted to hospital.

From these conclusions it is clear that accidental hypothermia is one of the major causes of death in this country during the winter months. Preventive measures must be taken seriously and the categories specially at risk need defining. General practitioners can help by reminding those in charge of old people or babies of the condition and telling them how to prevent it.

The importance of adequate heating in the home must be stressed, and the tradition that bedroom windows should be kept open needs to be overcome. More food is necessary in cold weather, though people who are short of money sometimes save on food to buy fuel. It should be more widely known that help in paying for fuel may be available during severe weather from the Ministry of Social Security. Improvement in the insulation of existing houses, as well as new dwellings, occupied by people liable to hypothermia might be considered. Registers of elderly people living alone should be compiled and the aid of neighbours secured to visit and help them during cold weather.

Periods when the mean environmental temperature is below $41^{\circ} \mathrm{F}$. ( $5^{\circ}$ C.) are specially important for infants and the aged and people suffering from debilitating diseases. During cold weather, therefore, a low-reading clinical thermometer registering $75^{\circ}-105^{\circ} \mathrm{F}$. $\left(23.9^{\circ}-40.6^{\circ} \mathrm{C}\right.$. $)$ should be ready for use, as with this instrument the diagnosis of hypothermia can be established beyond doubt. When the skin is cold beneath the clothing and when the ordinary clinical thermometer fails to reach $95^{\circ} \mathrm{F}$. $\left(35^{\circ} \mathrm{C}\right.$.), the low-reading thermometer should be inserted 2 in. $(5 \mathrm{~cm}$.) into the rectum and left in for five minutes. A temperature below $95^{\circ} \mathrm{F}$. $\left(35^{\circ}\right.$ C. $)$ is diagnostic of hypothermia. Hypothermic patients do not necessarily look ill, but they are sometimes pale or cyanosed, and the skin may have a puffy consistency. While some may be comatose, others may have no noticeable disturbance of consciousness even though severely affected.

Home conditions will usually be unsuitable for treating these patients. Care should be taken while moving them to hospital that they do not lose any more heat, and the heating system of ambulances should be checked for efficiency. Attempts at rapid warming are dangerous to the skin and possibly to life, and a $1^{\circ} \mathrm{F}$. $\left(\frac{1}{2}^{\circ} \mathrm{C}\right.$.) rise of rectal temperature per hour is probably about right, though reliable evidence on ideal rates of warming is not yet available. About $14 \%$ of the 126 patients in the report died hypothermic; the remaining deaths occurred after a normal temperature had been reached, sometimes after several days. Hospitals would therefore be well advised to retain all such patients in their wards for at least four to five days, even when they seem to be recovering well.

Accidental hypothermia is insidious and sometimes may be masked by concomitant disease. The key to diagnosis is to remember its existence. A hand placed on the patient underneath the clothing will find a cold skin, and a low-reading rectal thermometer will clinch the matter. There are not many serious illnesses which can be diagnosed so certainly in the home and none in which early diagnosis is more important.

\footnotetext{
1 Brit. med. F., 1964, 2, 1212.

2 Accidental Hypothermia in the Elderly, ibid., 1964, 2, 1255. Report of the Committee on Accidental Hypothermia, Royal College of
} 